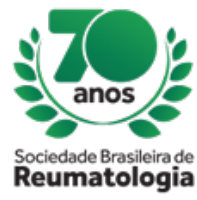

\title{
SMALL CELL LUNG CARCINOMA PRECEDED BY DERMATOMYOSITIS
}

Leandro Diniz Garcia (UNIFENAS- - Universidade José do Rosário Vellano, Alfenas, MG, Brasil), Clara Monteiro Reis (UNIFENAS- - Universidade José do Rosário Vellano, Alfenas, MG, Brasil), Bianca Rodrigues Mota (UNIFENAS - Universidade José do Rosário Vellano, Alfenas, MG, Brasil), Paloma Lilian Andrade Pedroso (UNIFENAS - Universidade José do Rosário Vellano, Alfenas, MG, Brasil), João Pedro Cachero LIno (UNIFENAS - Universidade José do Rosário Vellano, Alfenas, MG, Brasil), Lívia Maria Carvalho Lima (UNIFENAS - Universidade José do Rosário Vellano, Alfenas, MG, Brasil), Anna Clara Fachetti Carvalho (UNIFENAS - Universidade José do Rosário Vellano, Alfenas, MG, Brasil), Gabrielly Souza Gonçalves (UNIFENAS - Universidade José do Rosário Vellano, Alfenas, MG, Brasil), Lara Lopes Fonseca Silva (UNIFENAS - Universidade José do Rosário Vellano, Alfenas, MG, Brasil)

\section{BACKGROUND}

Dermatomyositis is an autoimmune inflammatory myopathy considered rare, characterized by symmetrical proximal muscle weakness and typical cutaneous rash (heliotropic rash, Gottron's papules and rash in the areas of photoexposure). Dermatomyositis can be confirmed with the help of Bohan and Peter criteria, which consider the clinical signs of proximal muscular weakness, the serum search for skeletal muscle enzymes (CK, Aldalase, LDH, TGO and TGP), myopathic changes in electromyography and muscular biopsy with characteristics characteristic of myositis. In some cases, the disease is associated with an increased risk of malignancy,

with a higher incidence of lung and ovary cancer, with small cell lung carcinoma being one of the most recurrent, making it imperative to confirm the diagnosis, the investigation of association of the disease with a possible neoplasia.

\section{CASE REPORT}

A 53 years old, black man, rural worker, started arthralgia, myalgia, progressive dysphagia, proximal paresis of upper and lower limbs and important weight loss beginning 3 months ago. Physical examination showed exanthematous desquamative lesions in the trunk and abdomen region and presence of heliotrope in malar region. Laboratory tests were requested for etiological research evidencing $\mathrm{Hb} 10.3$, 10,710 leukocytes, $4 \%$ lymphocytes, 243,000 platelets, CPK 3090, aldolase 17.8, TGO 88, TGP 53.A 53 years old, black man, rural worker, started arthralgia, myalgia, progressive dysphagia, proximal paresis of upper and lower limbs and important weight loss beginning 3 months ago. Physical examination showed exanthematous desquamative lesions in the trunk and abdomen region and presence of heliotrope in malar region. Laboratory tests were requested for etiological research evidencing $\mathrm{Hb} 10.3,10,710$ leukocytes, $4 \%$ lymphocytes, 243,000 platelets, CPK 3090, aldolase 17.8, TGO 88, TGP 53 . Due to the result of the chest $\mathrm{x}$-ray and the progressive dysphagia clinic, and to the weight loss table, a contrast chest tomography was performed, allowing the identification of mediastinal lymph node enlargement associated with expansive infiltrative lesion in the middle / previous mediastinum region, with pathology compatible with small cell lung tumor.

\section{CONCLUSION}

The diagnosis of dermatomyositis in this case was confirmed by positive clinical and laboratory tests, excluding the need for biopsy and electroneuromyography. Therefore, the investigation of hidden neoplasms should be initiated, since the association of dermatomyositis with neoplasia and the lack of clinical improvement of the patient in the first year of treatment are factors of poor prognosis, once the patient usually shows a good response to the use of corticotherapy. 